\title{
GESCHIEDENIS VAN DE NEDERLANDSCHE BOVENWINDSCHE EILANDEN
}

DOOR

\author{
PROF. DR. L. KNAPPERT
}

\section{HOOFDSTUK III (Vervolg)}

$\S 15$. Van zending door de Hernhutters heb ik op onze eilanden geen sporen gevonden. Wel heeft de graaf van Zinzendorf St. Eustatius bezocht. Hij was 26 December 1738 met het schip St. Maarten van Texel uitgevaren en 27 Januari 1739 op St. Thomas aangekomen. Nadat hij daar de belangen der Broedergemeente naar vermogen behartigd had, waarbij hij zich van de Nederlandsche taal bediende, voer hij 16 Februari 1739 over St. Kruis en St. Eustatius naar Europa terug $\left.{ }^{1}\right)$. Op ons eiland was toen commandeur Isaäc Faesch, dien wij natuurlijk nog ontmoeten zullen en die 29 December van dat jaar tot directeur van Curaçao zou benoemd worden, maar ik heb nergens in zijne brieven en rapporten van dat bezoek melding zien maken.

Doch van de geschiedenis der Hernhuttersche zending op de Deensche Antillen moeten wij toch eene bladzijde opslaan, omdat daarbij Nederlandsche predikanten betrokken zijn. Gelijk eigenlijk bij alles op St. Thomas het Nederlandsch betrokken is. Onze taal was daar nog heerschend op 't eind der 17de eeuw, in de middagkerk werd in die taal gepreekt, de Deensche overheid gebruikte haar voor officiëele bekendmakingen, wat tot ver in de 18de eeuw heeft geduurd. Het zijn - droevig spel der historie! - de vluchtelingen van ons St. Eustatius geweest, in 1781, die, zelven Engelsch sprekend, op St. Thomas het Nederlandsch hielpen verdringen. Maar het Negerhollandsch der Deensche Antillen is het duidelijkst bewijs van den overwegenden invloed, dien onze taal daar geoefend heeft, dat Negerhollandsch, waarin de Hernhutters

1) Oldendorp, a. w. II 583. 600. Westergaard a.w. blz. 159 noemt hem niet! Adolf Schulze, Abrisz einer Geschichte der Brizdermission 1901 S. 12. Von Dewitz,In DänishWest-Indien. Anfänge der Brider Mission in St. Thomas, 1899. 
predikten en hun zendingslectuur drukten, waarin de Deensche regeering nog in 1818 een Nieuw Testament ter perse legde ${ }^{1}$ ).

Wij zullen later zien, dat de gereformeerde gemeenten door $\mathrm{Ne}-$ derlandsche predikanten bediend werden en dan ook van hare lotgevallen verhalen; thans is er ons aan gelegen te zien, hoe de verhouding was tot de slavenzending der Broeders. En dan vertoont zich hetzelfde droevige feit als in Suriname: zelven niets doende, werkten de Nederlandsche predikanten op St. Thomas de zending der Hernhutters tegen ${ }^{2}$ ).

$\S 16$. In 1739 stond daar Joh. Borm. Hij was de jonge missie zóó vijandig gezind, dat hij de bevolking telkens tegen de Broeders en de gekerstende slaven ophitste. Hij was de verklaarde vijand van de voortreffelijke Friedrich Martin, Mattheus Freundlich en zijn vrouw Rebekka, eene mulattin, die juist toen, ook door zijn aanstoken, in de gevangenis waren geworpen. Zinzendorf trachtte hem door brieven tot betere gedachten te brengen, ja bracht hem zelfs nog op den dag van zijn vertrek een persoonlijk bezoek - het mocht niet baten ${ }^{3}$ ). Toen heeft de macht des konings de woede des ijveraars getemd. Men weet, dat de gekerstende negers zich tot den koning, de negerinnen tot de koningin van Denemarken (Sofia Magdalena v. Brandenburg Kulmbach) in een treffend smeekschrift richtten en dat $Z$. M. daarop het volgend besluit nam d.d. Frederiksborg 13 Maart 1739: Wij Christiaan VI bij de genade Gods Koning van Denemarken, Noorwegen enz. Friedrich Martin is door den bisschop der Boheemsche Broeders David Nitschmann gewijd tot Christi zendeling tot de zwarten van St. Thomas en St. Croix. De gereformeerde predikant heeft zich daarover beklaagd bij den gouverneur. Maar nademaal zoowel onze als de gereformeerde predikanten niet verder beroepen zijn dan tot werk onder de ordentelijke gemeenten en niet onder de heidenen. En, nademaal wij tot hiertoe allergenadigst hebben getolereerd de Moravische en Boheemsche Broeders, willen wij ook dat deze leeraar daar getolereerd worde. De gouverneur zal zorg dragen, dat de predikanten zich niet bemoeien met deze Boheem-

1) Men zie vooral het reeds in den vorigen jaargang blz. 366 noot 2 genoemde boek van Hesseling, Het Negerhollands, 1905 en de studie van De Josselin de Jong over diezelfde creoolsche taal.

${ }^{2}$ ) Een soortgelijk getuigenis van de Engelsche predikanten op Jamaica bij J. A. Froude, The English in the West Indies, pag. 205. Over den arbeid der Hernhutters oordeelt ook hij bijzonder gunstig, t. a. p. en pag. 220. Zoo doet ook Bryan Edwards $a$. $w$. I 487-495, die voor 1787 als door de Broeders bekeerde slaven opgeeft: Antigua 5465, St. Kitts 80, Barbados en Jamaica 100, Deensche Antillen 10.000, Suriname 400.

) Oldendorp $a . w$. II. 588 . 
sche gemeenten of met de door haar bekeerde negers en Friedrich Martin niet met hen ${ }^{\mathbf{1}}$.

Ds. Borm ontving 3 Juli een afschrift van dit allerkoninklijkste bevel en had voortaan zijn woede te beteugelen. Hij zond een copie ervan aan classis Amsterdam en troostte zich met de overweging, dat het werk dezer Hernhutters toch weinig vrucht droeg. Slechts wilde hij gaarne weten, wat hij moest denken van den doop dezer ,zoogenaamde" Hernhutters? $\left.{ }^{2}\right)$ Het ware voor zijn eigen zieleheil beter geweest, zoo hij zijn leven gebeterd en zijn bijzit vroeger dan op zijn sterfbed getrouwd hadde ${ }^{3}$ ).

$\S 17$. Het schitterend voorbeeld der Hernhutters moest toch op den duur wel tot navolging prikkelen. Zoo deed het althans Henricus Müller, Nederlandsch hervormd predikant op St. Kruis. Zijne voorgangers zullen wij in ander verband noemen, hij stond er sinds $1774^{4}$ ) en blijkt ook aan zending onder de negers veel te hebben gedaan. Zijne gemeente bestond uit 200 lidmaten, van wie $\frac{1}{3}$ zwart. Toen hij op het eiland kwam, vond hij bij die negers weinig kennis, zij werden lidmaat na een klein boekje van weinig bladzijden uit het hoofd te hebben geleerd. Ook was veler levensgedrag in het oog loopend goddeloos. Hij trok zich hun betering aan en werd van meening, dat deze menschen niet liefderijk genoeg onderhouden en vermaand werden, maar in plaats van als broeders der gemeente als slaven behandeld. Daarom sloeg hij zijn kerkeraad voor om, met „toetrekking” der gemeente, uit de vrije negers ouderlingen te kiezen. Zoo geschiedde en sedert beterde de toestand merkelijk. Om hunne onkunde „af te helpen" schreef hij een klein boekje, „Kort en eenvoudig onderwijs voor een heyden, die zich tot den christelijken godsdienst begeven wil" en liet dat drukken. Hij gaf onderricht aan de mannen en jongens, zijne vrouw aan de „vrouwens” en jonge dochters. Maar dat ging langzaam, omdat hij dagelijks ook nog twee uren catechisatie voor blanken had. Daarom stelde hij nog een schoolmeester bepaaldelijk voor de negers aan, een lid van zijn kerkeraad, na examen benoemd en wel op zulk een salaris, dat hij de slaven om niet en de vrije negers voor weinig leeren kon. Bij de aanneming was dit voorts eene moeielijkheid, dat hun doop onzeker was. Velen van St. Thomas gekomen, vertelden aan ds. Müller, dat zij daar in hun

1) Oldendorp $a$. $w$. II 616 noemt het rescript ook gedagt. 13 Maart 1759, zegt dat het begin Juni op St. Thomas aankwam, maar noemt niet den inhoud.

2) Oud Class. Archief Amst. W. I. eilanden, afd. St. Thomas blz. 2. Joh. Borm en Kerkeraad aan classis 12 October 1739 , aldaar blz. 2 v.

3) J. P. Knox, A historical account of S. Thomas, 1852, p. 139.

‘) Naamregister der predikanten in de .... Bat. Republiek, 's Grav. 1806, blz. 194. 
jeugd door een roomschen priester gedoopt waren, die van eiland tot eiland reisde ${ }^{1}$ ) en zonder belijdenis doopte. Hoe moest men met zulke negers doen? Een doopbewijs konden zij hem niet toonen en hun ouders waren vaak nog heidenen. Aannemen of doopen? Ds. Müller was voor het laatste, ook omdat hij den doop der papisten niet voor wettig hield (op welk punt hij dus niet goed gereformeerd was). Hij had nog andere vragen, die alle getuigen van zijne belangstelling in de slavenbekeering. Wanneer een slaaf ter dood is veroordeeld, mag men hem dan in den kerker nog doopen? En, zoo hij reeds gedoopt is, hem het avondmaal toedienen? Is voor den doop van een vromen slaaf de toestemming van den eigenaar noodig? 2) Hoe heerlijk, roept ds. Müller uit, zegent God het pogen der Deensche zendelingen in Oost-Indië! $\left.{ }^{3}\right)$ En hier der Moravische broeders! En zou dan de zuiverder leer der Hervormde Kerk minder aannemelijk voor de heidenen zijn? Aldus de voortreffelijke man, en hij vraagt de classis om raad, ofschoon hij als Deensch onderdaan zich zijne vrijheid tegenover haar voorbehoudt ${ }^{4}$ ).

$\S 18$. Twee maanden na dien brief deed hij met zulk een slavendoop eene smartelijke ondervinding op. Zekere slavin Marotte had hij gedoopt en den naam Anna Maria gệgevèn $\left.{ }^{5}\right)$. Hāe meesteres had haar deswege bloedig doen geeselen. Wel onderzocht de Deensche gouverneur het geval en beloofde volgens de koninklijke wet zijne bescherming, maar intusschen was het arme schepsel door de tuchtiging krankzinnig geworden en aan den ketting gelegd. En haar meesteres zwoer, dat zij daarin sterven zou. „Ketenen en banden schijnen nog soms de belijdenis des evangeliums te volgen" ${ }^{6}$ ).

1) Aldus eenmaal ook Steven van der Haghen: „'t Is al de Portugisen-padres diese prisen, dat sulcken godvruchtige mannen waren, haer niet ontsagen vant eene eylandt aent ander te gaen...." d.d. Casteel van Amboina 14 Aug. 1617, Grothe, Archief oudholl. zending. V 85 vlg. Doch predikanten als Heurnius en Wiltens bleven bij hen niet achter.

2) Ja, en op de Deensche Antillen ook van den gouverneur, Oldendorp a. w. II 521.

ग) De door Frederik IV van Denemarken in 1705 gestichte zending in Trankebar aan de kust van Koromandel, waaraan vooral de namen van Heinrich Plütschau en Bartholomeüs Ziegenbalg verbonden zijn. Van des laatsten Malabarisches Heidentum bezorgde Caland eene uitgave, 1926. Voor de 19de eeuw Hans Gehring, Land und Volk der Tamulen, Gütersloh 1899. A. Gehring, Das Tamulenland, seine Bewohner und die Mission, Leipzig, 1927.

4) Henricus Müller aan classis Amsterdam d.d. Christianstadt, St. Kruis, 15 Jan. 1775, oud class. archief, W. I. eilanden, afd. St. Kruis, blz. 1.

- Eene andere Marotte, maar onder de Hernhutters op St. Thomas, na haren doop Magdalena, 1739, bij Oldendorp a. w. II 589 en twee Anna Maria's aldaar register in voce.

๑) Extract uit Kerkel. Acte boek St. Kruis 4 Maart 1775, oud class. archief, afd. St. Kruis blz. 2. 
In dezen zelfden tijd bracht zekere Herman van Tiel op St. Kruis eene beschuldiging tegen ds. Müller en zijn kerkeraad, ouderling Joh. Rogiers en diakenen Pieter Rogiers en Jac. de Veer, in, als zou de gemeente in menig opzicht van de Nederlandsche gereformeerde kerkorde afwijken. Om dit geschil te onderzoeken kwamen toen ds. Joh. Wilh. Brand van St. Thomas met zijn kerkeraad naar St. Kruis over. Wij zullen daarover later nog moeten handelen. Thans vermelden wij slechts, dat bij het hooren der partijen weder Müllers goede gezindheid jegens slaven bleek. Dat men zich bij den predikant moest aanmelden, wanneer men ten avondmaal wilde gaan (een der bezwaren van Van Tiel), geschiedde omdat er soms negers kwamen, die men niet kende en dus moest onderzoeken. Maar het uitreiken van biljetten van toelating - zooals b.v. in de gereformeerde kerk te Kopenhagen geschiedde - had ds. Müller afgeschaft, op verzoek van negers, die daaraan aanstoot namen en "men moet ook den minste geen aanstoot geven" ${ }^{1}$ ).

$\S 19$. Deze predikant Brand van St. Thomas was op dit punt geen geestverwant van zijn jongen collega op St. Kruis. Classis Amsterdam had na den brief van Müller zijn gevoelen gevraagd. Hij schreef toen een lang en zwartgallig antwoord terug, waarin hij sterk afgaf op zijne blanke gemeente o.a. omdat zóóveel christenen zich in ontucht met heidenen verliepen, dat de bastaarden in groote menigte langs de huizen bedelden. Maar de negers achtte hij niet beter. De classis had op zending onder hen aangedrongen, doch ds. Brand had daar weinig oor naar. Een goddeloos geslacht, die negers, bevlekt met alle zonden, ook met tooverij. Zij zoeken het christendom alleen om met de blanken gelijke voorrechten te genieten, om ook voor de openbare rechtbanken te mogen verschijnen, maar zij zouden nog altijd alle blanken op de drie eilanden willen vermoorden, zooals zij dat op St. Jan hebben gedaan ${ }^{2}$ ), zoo het zwaard der overheid hen niet in bedwang hield. Brand deed wel zijn best hen tot de waarheid te brengen, maar hen tot lidmaten aannemen, ging niet, tenzij zij in wettig huwelijk wilden treden en grondige kennis bezaten. Er was op St. Kruis ook een Engelsche predikant, Matthew, die in Christianstadt eene negerschool had opgericht, maar Brand achtte dat eene schadelijke concurrentie voor den gewonen schoolmeester. Wel is waar had men

1) Kerkeraadszitting op St. Kruis 4 Maart 1777 en verslag daarvan oud class. archief, afd. St. Thomas blz. 3.

2) De groote slavenopstand op St. Jan, uitgelokt o.a. door de vreeselijke strafwet van $\mathrm{Ph}$. Gardelin, gouverneur van St. Thomas, was eind November 1733 uitgebarsten. Er waren toen op St. Jan 109 plantages met 1087 slaven. 27 Mei 1734 was de opstand met Fransche hulp in bloed gesmoord, Westergaard a. w. pag. 166-175. 
die negerschool aan 's mans zoon toevertrouwd, maar Brand vond dat een gevaarlijk experiment, vermits die jongeling daardoor bloot stond aan de verleiding der jonge negerinnen in dit heete klimaat. De classis had hem ook gewezen op den zendingsijver van ds. Müller. Brand voerde daartegen aan, dat zulk een negerschool ook bij zijne gemeente op St. Thomas op te richten onnoodig, bedenkelijk en nadeelig zou zijn. Onnoodig omdat zijn schoolmeester, de Leidenaar Adr. de Hoogh, zoowel blanke als zwarte kinderen in talen, wetenschappen en de grondwaarheden der religie bereids onderwijst, algemeen bemind is en, leed hij schade, stellig zijn ontslag zou vragen. Bedenkelijk, omdat het oprichten van zulk eene negerschool ds. Brand's gemeente tegen hem opstandig zou maken. En eindelijk nadeelig, omdat de negers daardoor in hun hoogmoed zouden gestijfd worden. Ds. Brand wilde den ijver van ds. Müller gaarne volgen, voorzoover dat betamelijk was bij een leeraarsambt volgens de formulieren van het gereformeerd geloof, maar eene kerkregeering en -bediening als op St. Kruis wilde hij niet. Het was tegen zijn eed. Anderen (hij bedoelt natuurlijk ds. Müller!) mochten van onze gezette kerkwetten afgaan, het avondmaal van huis tot huis rondbrengen, hun dienst met koopmanschâppenen vèrmenengen - dat was zijn doen niet. Intusschen verlieten de negers zijne catechisatie en gingen naar St. Kruis om daar aangenomen te worden. Zeer begrijpelijk zochten zij milder bejegening. Maar ds. Brand kwelde zich met de vraag, of hij hen bij hun terugkomst niet op nieuw onderzoeken moest ${ }^{1}$ ). $\S 20$. De eigenlijke negerzending is op onze eilanden van de Wesleyaansche methodisten uitgegaan, onder voortdurende tegenwerking - het doet ons leed dat te moeten aantoonen — van het Nederlandsch bestuur. Het is waar, dat het vraagstuk uiterst moeilijk en samengesteld was.

John Wesley was een stellige vijand van alle slavernij en allen slavenhandel. Sterken indruk hadden op hem de boeken gemaakt van Anthony Benezet, de „Historical account of Guinea” en zijn "Caution to Great Britain" en, toen Wesley Woensdag 12 Februari 1772 een van deze beide gelezen had, was hij zeker van zijne houding tegen deze ,execrable sum of all villanies, commonly called the slave trade"'. Hij bekende nooit iets dergelijks in de oude heidenwereld gelezen te hebben en oordeelde, dat het stelsel in barbaarschheid alles wat christelijke slaven in Moslimsche landen

1) Ds. J. W. Brand aan classis d.d. St. Thomas 17 Juni 1778, oud class. archief afd. St. Thomas blz. 16. Dit stuk is ongedagteekend en breekt af zonder onderteekening; het vervolg met opschrift ligt enkele bladzijden verder. 
te lijden hadden nog verre overtrof ${ }^{1}$ ). Niet alle methodisten dachten zoo. George Whitefield, hun groote prediker, was volstrekt blind voor den gruwel der slavernij als slavernij; alleen de ruwheid van sommige meesters scheen hem zonde. Zijn bekende brief aan de Trustees van Georgië 1748 verdedigt de slavernij op voor ons pijnlijke wijze, ja hare invoering, waar zij nog niet bestond. In een lateren brief, aan Hervey, d.d. Maart 1751, beroept hij zich daarvoor, natuurlijk, op den Bijbel. Op Abraham die immers slaven had, en op de Gibeonieten die tot slaven werden gemaakt ${ }^{2}$ ). Daarentegen was een andere volgeling van John Wesley ook op dit punt zijn overtuigde geestverwant, en hij is het, dien wij op St. Eustatius gaan ontmoeten. Daarom spreken wij over hem wat uitvoeriger.

Thomas Coke is geboren in 1747 te Brecknock of Brecon, hoofdplaats van Brecknockshire in Wales, waar zijn vader burgemeester was ${ }^{3}$. Hij kwam 11 April 1764, gelijk zoovele andere „Welshmen”, in Jesus College te Oxford, werd ,doctor of civil law”, maar ging als curate naar South Petherton in Somersetshire, nog onbekeerd. Zijne eerste ontmoeting met Wesley geschiedde Dinsdag 13 Augustus 1776. „Ik had een lang gesprek met hem”, teekent Wesley aan, „het begin eener vereeniging, welke, naar ik vertrouw, nooit zal eindigen" "4). En zoo is het ook gegaan. Methodist geworden, smadelijk uit zijn ambt ontslagen, sloot hij zich te nauwer bij Wesley aan, die hem, man van rang en fortuin, tot generaal inspector voor Amerika bestemde. Philip Embury had daar het methodisme georganiseerd, na hem hadden kapitein Webb ${ }^{5}$ ), Boardman, Pillmoor, Asbury door gearbeid. Den 2 September 1784 wijdde Wesley Coke tot bisschop voor den arbeid in Ameri$\mathrm{ka}^{6}$ ). Den 18den verliet hij Engeland en vond in Amerika het

\footnotetext{
1) John Wesley, The Journal, ed. Nehem. Curnock, Standard Ed. V 445 s. op Wed. 12 Febr. 1772. Robert Southey, The life of Wesley etc. ed M. H. Fitzgerald. Oxf., 1925 II 256.

${ }^{2}$ ) James Paterson Gladstone, Georg Whitefield M. A. Fieldpreacher, N. Y. z. j. pag. 135. 254. 280.

s) Een foto van zijn geboortehuis te Brecon, een andere van hemzelven en een derde van zijn huis te Bristol als generaal superintendent in genoemd Journal VI tegenover pag. 120. Zie ook Diction. Nat. Biogr. XI in voce. Dit artikel noemt verscheiden Levens van Coke, door Crowthen, Drew, Etheridge, Moister en Sutcliffe. Van deze bezit en gebruikte ik J. W. Etheridge, The life of the Rev. Thomas Coke, Lond., Mason, 1860, met portret.

4) The Journal VI 120. Henry Moore, Life of Wesley, II 308 ss. Etheridge $a . w$. pag. 47.

5) „The captain is all life and fire; therefore, although he is not deep or regular, yet many who would not hear a better preacher flock together to hear him". The Journal V 497 op Dinsdag 2 Febr. 1773.

๑) De plechtige bul van aanstelling als superintendent onder Wesleys hand en zegel o.a. bij Southey, a. w. II 249. H. M. van Nes, John Wesley, blz. 148 vlg.
} 
methodisme in goede reuk, terwijl hij door zijn rang en beschaafde vormen nu ook vele aanzienlijken won. Op de conferentie te Baltimore constitueerde hij het methodisme als Episcopale Kerk met bisschoppen, oudsten en diakenen en wijdde Asbury tot bisschop ${ }^{1}$ ), terwijl hij 5 Juni 1785 Cokesbury College stichtte. Welnu, juist als Wesley (b.v. in zijn „Thoughts of slavery”) was Coke van den aanvang af een fel bekamper van den slavenhandel, preekte er tegen en zond een petitie aan het Congres voor de vrijlating der negers, die hij en Asbury zelven aan Generaal Washington te Mount Vernon overhandigden. Zijn heftig, fanatiek optreden wekte natuurlijk den tegenstand der slavenhouders, doch bovendien (en dit moeten wij zoo aanstonds op St. Eustatius in het oog houden) waren velen sterk gekant tegen de methodistische, bekende oplevingen, de „revivals” met zinsverrukkingen, kramptrekkingen, luide roepen om een vollen Jezus, helle-angsten, verlammingen - gelijk wij die ten onzent b.v. bij de Nijkerksche beroerten kennen. Wat niet weg neemt, dat er in 1786 alleen in Zuid-Carolina 22 kapellen waren en 6600 leden.

$\S 21$. Nu had Wesley in 1758 te Wandsworth, Surrey, twee negerslaven en een mulat gedoopt van Nathanaël Gilbert, een afstammeling van Sir Humphrey Gilbert en „Speaker” van het „House of Assembly" op Antigua ${ }^{2}$ ). Zijn broeder Francis had hem voor het methodisme gewonnen. Nathanaël keerde naar Antigua terug, na tevergeefs John Fletscher te hebben verzocht hem te vergezellen, en vormde daar een negergemeente van 200 leden, na zijn dood in 1778 geleid door John Baxter ${ }^{3}$ ). Ook eene Engelsche vrouw hield daar samenkomsten met slaven en in 1786 wordt de gemeente op 2000 negerslaven geschat. Op zijn tweede reis naar Amerika in dat jaar kwam Coke voor de kust van dit eiland; hevige stormen hadden het schip ver uit de koers gebracht; bij een daarvan had de kapitein, geen vriend der methodisten, bijna den bisschop, als een andere Jona, over boord gezet. Kerstmis 1786 kwam het gezelschap aan wal. Coke preekte er aanstonds onder grooten toeloop en ook planters en kooplui vierden hem. Want het methodisme was daar in eere, overmits het (anders dan gewoonlijk, ook bij ons, gevreesd werd) een goeden invloed op de slaven

1) Het getuigschrift d.d. 27 Dec. 1784 bij Etheridge $a$. $w$.pag. 114.

s) The Journal op Dinsdag 17 Jan. 1758, IV 247 s. Wesley teekent aan: „Shall not His saving health be made known to all nations?"

3) Over dezen voortreffelijken methodistenprediker, scheepstimmerman op Antigua "Daddy Baxter”, zooals de negers hem noemden, zie Findlay and Holdsworth, The history of the Wesleyan methodist missionary Society, Lond., 1921 II 32 s. 
oefende en hen ijverig in hun werk maakte. Hij liet nu Warrenner op Antigua en bezocht zelf met Baxter en twee anderen Dominica, Nevis, St. Vincent, waar Clarke zich vestigde en St. Kitts, waar Hammet arbeiden zou ${ }^{\mathbf{1}}$ ).

$\S 22$. Daarna kwam men op St. Eustatius, Januari 1787, toen daar gouverneur a. i. Johannes Runnels was. Deze had juist zekeren slaaf Harry, die in Amerika methodist geworden was, het prediken verboden, omdat hij „revivals” wekte. Toen Harry met preeken voortging had hij hem laten geeselen. Dit maakte de ontvangst niet hartelijker noch was het gunstig voor het verzoek, dat Coke van plan was te doen. Zaterdag 27 Januari 1787 ,stonden met de translateurs in judicio binnen Thomas Coke doctor, hebbende noch twee personen bij hem, verzoekende Coke dat elk dier twee mogte toegelaten worden hunne leer alhier te prediken, gevende ten dien eynde hunne credentialen en geloofsarticulen den heer president over. In advies gehouden". De eerstvolgende dagen heeft Coke toen nog gepreekt, waar hij kon, totdat Vrijdag 2 Februari „staan in judicio binnen Doctor Thomas Coke en Hammet, verzoekende bij interpretatie van P. Ouckama (den secretaris) dat de laatste zijn leer alhier mag prediken; hem gezegd dat ampt eerst hier te leeren, (dan) zes weken na St. Kitts en na verloop van dien tijd bij dugtige bewijsen derselfs nuttigheid aan te toonen, om diena (daarna) nader te disponeeren, met probitie (sic) om voor die dispositie hier geen (sic) dienst te doen". ${ }^{2}$ ) Uit dit bargoensch schijnt te blijken, dat de gouverneur geen missie op het eiland wilde en het vervolg bevestigt dit vermoeden. Coke vatte het ook zoo op en schudde het stof van zijn voeten. Hij nam passage op een Hollandsch schip naar Charleston, door zijne zwarte vrienden uitgeleide gedaan en van alles voorzien. Hij prijst den kapitein, die de bemanning uit de Schrift placht voor te lezen, wat Coke hoorde dat op Hollandsche schepen niet ongewoon was.

$\S 23$. In 1788 deed Coke, deze Xaverius van het methodisme ${ }^{3}$ ), zijn derde reis naar de West-Indiën, preekte op Barbados, Dominique, overal met groot succes, maar stootte op St. Eustatius we-

1) Dit naar Findlay $a$. $w$. II 37-40 en Southey $a$. w. II 267-272, Etheridge $a$. $w$. pag. 159-167. Dominica, niet te verwarren met San Domingo, dat naar St. Dominicus heet, terwijl Dominica, tusschen Martinique en Guadeloupe, aldus door Columbus benoemd werd, omdat hij het op Zondag ontdekte.

$\left.{ }^{2}\right)$ Extract uit notulen van den Raad van St. Eustatius op beide data (ongepagineerd). R. A. De metgezel van den bisschop heet hier Amet, wat wel de (Zeeuwsche?) uitspraak en dus schrijfwijze voor den in den tekst genoemden Hammet zijn zal. Findlay a. $w$. II 40 s. Etheridge $a$. w. pag. 169.

3) Hij las op een zijner reizen met warme bewondering een Leven van St. Franc. Xaverius.

West Indische Gids XII 
der het hoofd. Hij vond daar Harry niet meer. Die had toch samenkomsten met slaven gehouden en gouverneur Runnels had hem daarop weder laten geeselen en naar Amerika verkoopen ${ }^{1}$ ). Ook had hij bij plakkaat iederen blanke verboden gebedssamenkomsten met zwarten te houden op zware boeten en eindelijk verbanning voor den blanke, op geeseling reeds bij de eerste maal voor den slaaf. De bisschop vond dit vervolging tegen den godsdienst zelf. De Romeinen, zeide hij, vervolgden de christenen omdat zij vreemde goden invoerden; de roomschen de protestanten, omdat zij ketterijen leerden; maar hier gaat het tegen het gebed, dat immers voorwaarde is voor Gods zegeningen ${ }^{2}$ ). Toch was er op het eiland eene gemeente van 258 negers. Na een verblijf van slechts één nacht op het eiland vertrok Coke Donderdag 1 Jan. 1789. Doch de sloep, waarmede hij naar St. Kitts zou oversteken, kwam in aanvaring met een schip en moest terug. Onze zendeling zag daarin een teeken van de Voorzienigheid, besloot te blijven, huurde een groot vertrek en hield daar openlijke godsdienstoefening voor de negers. Maar „Hollandsche gouverneurs zijn er geen menschen naar om te lijden, dat men hun bevelen ongestraft in den wind slaat". Runnels liet hem aanzeggen, dat hij noch voor blanken noch voor zwarten preeken mocht op straffe van arbitraire correctie en daarna verbanning. „Wij antwoordden, dat wij zouden gehoorzamen, en niets meer op dat eiland van tirannie, onderdrukking en zonde te doen hebbende, keerden wij naar St. Kitts terug, God dankend voor een Britsche wetgeving en een Britsch bestuur" " $)$.

Runnels had Harry's prediking niet geduld, ook omdat zij de hoorders tot vlagen van zinsverrukking bracht. Had Dr. Coke daarover van den aanvang af zijne afkeuring uitgesproken, dan ware er misschien niet zoo iets ergs gebeurd. Maar hij beschouwde ze als de uitwendige teekenen der inwendige genade, en de gouverneur, ziende, dat Coke Harry als mede-arbeider beschouwde, hield hen allen voor lastige dwepers en behandelde hen dienovereenkomstig. Nu had de bisschop een derden metgezel, Brazier, op St. Eustatius achtergelaten, natuurlijk met de bedoeling, dat hij toch prediken zou. De gouverneur ontdekte hem en vergenoegde zich met hem uit te wijzen. Een aanzienlijke eilander, „in wien iets van het godsdienstige van het oudhollandsch karakter was overgebleven" bracht hem naar Saba. Coke prijst dit eilandje om zijn

1) Coke vond hem daar later als vrijgelatene en ijverig prediker terug.

2) Findlay, $a . w$. II 45. Southey, $a$. $w$. II 274. Etheridge $a$. w. pag. 184.

ग) Bij Southey, a. w. pag. 275. Etheridge a. w. pag. 185. Findlay a. w. II 46. 
zuivere lucht en vruchtbaren grond. Er was daar voor 3000 bewoners, van wie $\frac{1}{3}$ blanken, wel een kerkgebouw, maar geen predikant, en dat sinds 17 jaar $^{1}$ ). De vice-commandeur, de raad en de burgerij drongen er sterk op aan, dat Brazier daar als hun voorganger blijven zou en boden hem huis en bezoldiging aan. Coke kwam daarop ook naar Saba, verheugde zich over dezen gang der dingen en gaf gaarne zijne toestemming. Maar toen gouverneur Runnels er van hoorde, beval hij aanstonds den man te verjagen tot groote smart der bevolking ${ }^{2}$ ).

$\S 24$. Den 10en December 1790 is de onvermoeide bisschop voor de derde maal op St. Eustatius geweest en heeft zijne opwachting gemaakt bij den nieuwen commandeur, Pieter Anthony Godin, in 1789 uit Holland gekomen. Ook nu was de ontvangst alweder onvriendelijk genoeg, maar het methodisme zelf bloeide er met niet minder dan 200 leden, onder wie ook vrije negers en acht vermaners. $\mathrm{Zij}$ onderhielden betrekkingen met de gemeente op St. Kitts. Coke, bevreesd het vuur der oude vijandschap weder feller te zullen doen ontbranden, waagde het niet er te preeken en stak aanstonds over naar Nevis ${ }^{3}$ ).

Twee jaren later, 1792, weder in December, kwam de moedige man ten vierden male naar ons eiland. Hij vond er niets verbeterd, de geest der vervolging was nog vaardig over de regeerders en de kleine methodistische slavengemeente hield zich met moeite staande ofschoon, zegt Coke, hare "meetings" de eenige eeredienst waren, die nog op het eiland bestond. De gouverneur (dat was toen weder dezelfde Joh. Runnels, die na Godin a. i. was opgetreden) ontving hem met „de gewone bitterheid”. Erger, dat hij de methodisten bloedig vervolgde. Juist enkele dagen vroeger had hij twee negerinnen laten geeselen, omdat zij eene methodiste „meeting" hadden bijgewoond. Toen de zweep van den beul bloedende voren in haar ruggen sneed, riepen zij, dat zij deze martelingen boven al het goud en zilver der wereld verkozen en gaven zóóveel blijken van geduld en moed, dat sommige heeren, die er bijstonden, de strafoefening luide afkeurden. „Maar niets vermocht den gouverneur zachter te stemmen" ${ }^{4}$ ).

1) In 1755 was op Saba ds. Hugh Knox gekomen van de Presbyterianen en te New York geordend, G. van Essen aan cl. Amsterdam, dd.. St. Eust. 26 Febr. 1756, oud class, archief, W. Indiê, afd. St. Eustatius, blz. 20. Knox zou dan tot 1771 moeten gebleven of toen overleden zijn.

2) Findlay $a w$ II $46 \mathrm{~s}$. Hij noemt den gouverneur telkens Rennels. De noot aldaar pag. 54 geeft Runnels.

3) Etheridge a.w. pag. $204 \mathrm{~s}$.

๑) Aldaar pag. 246. Findlay, a. w. II 54. 


\section{NEDERLANDSCHE BOVENWINDSCHE EILANDEN}

Wij schamen ons over dezen Hollandschen wreedaard. Hem moet de vrees gedreven hebben voor die genoemde "revivals", maar veel sterker nog die andere - en zij was de allesbeheerschende in de gansche toenmalige slavenhoudende wereld - dat de gekerstende, onderwezen, eenigszins ontwikkelde neger zijn slavernij als onduldbaar beschouwen en begeeren zou, om er aan te ontkomen. Vader Labat zeide reeds in zijn tijd, dat de Engelsche geestelijken op Jamaica geen zwarte kindertjes doopten, omdat christenen geen slaven konden zijn en men daarom slaven geen christenen moest maken ${ }^{\mathbf{1}}$ ). Wij herinneren daar intusschen niet aan, om Runnels schoon te wasschen. Bovendien had hij moeten bedenken, dat op al de omliggende eilanden de ondervinding had geleerd, dat het methodisme den slaven juist arbeidzaamheid aanprees en men het daarom beter gezind werd.

Intusschen, ook voor St. Eustatius, „les idées marchent”. In 1811 gaf de, toen Engelsche, gouverneur Barrow den methodisten, onder wie toen als zendeling Myles Coupland Dixon arbeidde, vrijheid van godsdienstoefening. Maar .... er mochten geen samenkomsten zijn, waardoor slaven aan hun arbeid werden onttrokken; de zendelingen mochten de slavenhouders geen aanstoot geven; slaven mochten niet ten âvondmââl zonder vergunnining hünner meesters; er moest gepredikt worden in een „orthodoxen en fatsoenlijken stijl, zonder de stuiptrekkende bewegingen thans bij hen in zwang" '2). Dixon tartte de regeering, om één voorbeeld te noemen, dat bekeerde negers ongeschikt voor hun werk werden. In 1815 volgde Jonathan Raynar hem op. Op het oogenblik zijn, gelijk men weet, de protestantsche gemeenten op St. Maarten ${ }^{3}$ ) en St. Eustatius wesleyaansch methodist, bediend resp. door de zendelingen C. M. J. Darrell en C. Clark (op $f 1800$ !), terwijl op Saba de Anglikaansche geestelijke F. E. Prior arbeidt.

1) Vergel. J. A. Froude, The English in the West-Indies, 1888. pag. 205.

2) Ms. Hamelberg, K. Bibl, 120 B. 3, blz. 75. Opmerkelijk dat toen de dochter van Runnels eene ijverige methodiste klasleidster op St. Eustatius was! Findlay $a$. $w$. II 156 noot.

3) Op St. Maarten had John Hodge, een vrije kleurling van Anguilla, in 1817 het methodisme gebracht, eerst in het Fransche gedeelte, vanwaar het ook naar het Nederlandsche kwam. Onder zendelingen als Gilgrass, Cullingford steeg het aantal gemeenteleden er tot 409 (in 1829), onder wie ook vele blanken. Toen in 1849 de slavernij op Fransch St. Maarten ophield, vluchtten vele slaven van het Hollandsche gedeelte daarheen, maar onder hen geen van de honderden methodiste negers, Findlay $a$. $w$. II 170$172,385$. 